\title{
Effects of proprioceptive neuromuscular facilitation techniques in treating chronic nonspecific low back pain patients
}

\author{
DOI: https://doi.org/10.5114/pq.2020.100273
}

\author{
Khaled Z. Fouda', Ibrahim M. Dewir², Mohammed S. Abdelsalam ${ }^{3}$ \\ ${ }^{1}$ Department of Basic Science for Physical Therapy, Faculty of Physical Therapy, Cairo University, Giza, Egypt \\ ${ }^{2}$ Department of Physical Therapy, College of Applied Medical Sciences, Taif University, Taif, Saudi Arabia \\ ${ }^{3}$ Department of Physical Therapy for Musculoskeletal Disorders and Its Surgery, Faculty of Physical Therapy, \\ Cairo University, Giza, Egypt
}

\section{Abstract}

Introduction. As one of the highly prevalent musculoskeletal disorders, low back pain incurs high medical care costs. Proprioceptive neuromuscular facilitation has been used in treating chronic low back pain. This study aimed to investigate the effects of multiple proprioceptive neuromuscular facilitation techniques on endurance of the trunk musculature, spinal mobility, and impairment of function in cases of chronic low back pain.

Methods. Patients in this study were randomly assigned into 3 groups. Group A received rhythmic stabilization training, group $B$ received a combination of isotonic exercises, while group $C$ received a combination of both rhythmic stabilization training and combination of isotonic exercises. Trunk endurance was evaluated with trunk flexion and trunk extension endurance tests, spinal mobility was assessed with a modified Schober test, and functional impairment was measured with Oswestry Disability Index.

Results. ANOVA showed significant differences $(p<0.05)$ among the groups after treatment in the measured outcomes. Tukey's honest significant difference post-hoc test revealed a highly statistically significant improvement in the measured outcomes of group $\mathrm{C}$ in comparison with the other groups in the post-intervention conditions.

Conclusions. The application of the rhythmic stabilization training technique of proprioceptive neuromuscular facilitation followed by a combination of isotonic exercises was more effective than implementing either technique alone in the treatment of patients with chronic low back pain.

Key words: rhythmic stabilization training, combination of isotonic exercises, low back pain

\section{Introduction}

Low back pain (LBP) is one of the commonest musculoskeletal disorders, and one of the most demanding ones in costs of care and medical attention. It was stated earlier that $70 \%$ of adults would experience LBP at least once over their lifespan. Furthermore, over $80 \%$ of such patients report recurrent episodes [1].

Chronic LBP is referred to as pain in the lower back, particularly in the lumbosacral region of the back, lasting over 12 weeks. Patients commonly have limited range of motion and dis-coordination in the function of various body parts due to pain [2, 3]. Nonspecific LBP is described as pain that has no specific pathology as infection, neoplasm, etc.; rather, it might develop for mechanical reasons. It is characterized by heavy pain worsening with exertion, especially in the afternoon, and reliving with rest [4]. Moreover, the application of faulty ergonomic principles may be a cause of LBP or worsen its symptoms [5].

Exercise is the most current and frequently used modality for rehabilitation of patients with chronic LBP. Exercises target gaining muscle strength and endurance, in addition to flexibility of the back muscles and soft tissues [6]. Furthermore, fascial manipulation has proven to be effective in the treatment of chronic LBP, and it is important to restore the normal life activities [7].

Exercise programs for chronic LBP management differ in their structures. These differences are related to duration of exercises, their intensity, and the mode and frequency of training [8]. Various forms of dynamic exercise programs have shown favourable outcomes in treating back pain. Nevertheless, isometric training also brought about positive outcomes in managing LBP [9-16].

In this regard, different proprioceptive neuromuscular facilitation (PNF) exercises have been used to treat chronic LBP, including both isometric and isotonic ones [9]. For instance, a commonly applied technique that involves isometric contractions is rhythmic stabilization training (RST), which both provides stabilization and helps with the cases in which weakness is a main factor [17].

On the other hand, combination of isotonic exercises (COI) is a dynamic technique that uses isotonic contraction to manage strength and range of motion defects, besides enhancing the performance of controlled purposeful movements [18]. Few studies investigated the effect of PNF training on chronic LBP [9-11]. The efficiency of these exercises in the treatment of chronic LBP is not consolidated yet, and needs further research to provide sufficient evidence.

Also, it is important to investigate the combination effect of both static and dynamic patterns of PNF on chronic LBP. So, the purpose of this study was to investigate the influence of multiple PNF techniques on endurance of the trunk musculature, spinal mobility, and impairment of function in cases of chronic LBP.

Correspondence address: Khaled Z. Fouda, Department of Basic Science for Physical Therapy, Faculty of Physical Therapy, Cairo University, 7 Ahmed El Zayat Street, Bein El Sarayat, Giza 12612, Egypt, e-mail: kzfouda2004@yahoo.com 


\section{Subjects and methods}

\section{Patients}

Sixty patients who suffered from chronic LBP of both genders were recruited for this study from the outpatient physical therapy clinics in Cairo University hospitals. The patients were diagnosed by the referring orthopaedist, and then they were checked against inclusion/exclusion criteria prior to inclusion. The inclusion criteria involved complaining of LBP for more than 3 months, LBP appearance during or after activity, sitting, and stair climbing. The exclusion criteria were previous or concurrent diagnoses of spinal fractures, spinal canal stenosis, inflammatory disease of the spine, spondylolysis, spondylolisthesis, or spinal deformities [19].

Patients who met the inclusion/exclusion requirements were asked to participate, with an assurance that their data were to remain confidential and to be used anonymously in the analysis for the purpose of the study only. The participants had the right to withdraw from the study at any time.

\section{Research design}

A pre-post-test randomized clinical trial was performed. Randomization involved a random number generator software (Random.org); 3 independent groups of 20 numbers each were created from the range of numbers 1-60 without repetition, and a blind draw was carried out to select which set of numbers would represent each of the study groups. Each patient was asked to select a number in an opaque envelop. In accordance with this concealed selection, each subject was allocated in the group to which their number belonged.

\section{Outcome measures}

\section{Trunk endurance}

Static trunk flexors and extensors endurance was evaluated. During the trunk flexors endurance test, the patients sat on a testing table with their trunks supported against a prefabricated wedge that maintained their trunks at $60^{\circ}$ inclination from flat supine lying position. The hips and knees were kept flexed to $90^{\circ}$ bilaterally. Stabilization belts were fixed around the patients' waists and over the dorsum of their feet. The subjects put their arms across their chests, resting their hands comfortably on the opposite shoulders. For testing, the examiner asked the patients to maintain their trunks positioned at $60^{\circ}$ as the prefabricated wedge was moved back away from them for a $10-\mathrm{cm}$ distance. The outcome parameter was the time they could maintain this position. The trial was stopped when the patients visually re-established contact with the wedge [20].

Trunk extension endurance was evaluated while the patients were positioned in prone lying. The lower body was stabilized to the table by using straps around the ankles, knees, and hips. Patients' trunks were kept outside the testing table, with the upper border of iliac crest just at the edge. A chair was placed under the upper trunks and patients used their arms to position their upper bodies in a horizontal position. To start the test, the participants were asked to cross their arms ahead of their chests, resting their hands on the opposite shoulders. The outcome was the time elapsed from the start of the test until the subjects visually deviated from the horizontal plane [21].

\section{Spinal mobility}

A modified Schober test was used to measure spinal mobility. Flexion mobility was evaluated while the patient stood erect and the distance between both feet equalled 2 feet length apart. Three marks were set on the patients' backs: (1) at the lumbosacral junction, (2) $10 \mathrm{~cm}$ above the first point, and (3) $5 \mathrm{~cm}$ below the first point. The subjects were asked to bend forwards as much as they could; then, the distance between marks 2 and 3 was measured. To assess flexion mobility, we calculated the measured difference between maximal flexion position and the starting position. Extension mobility was evaluated by asking the patients to bend backwards as much as they could and then measuring the distance between marks 2 and 3 again. To assess extension mobility, we calculated the measured difference between maximal extension position and the starting position [22].

\section{Functional impairment}

The Arabic version of Oswestry Disability Index (ODI) was used to measure the level of functional impairment. ODI contains 10 items related to limitation in daily living activities; it is widely applied to monitor treatment effects with regard to changes in the functional mobility of patients with chronic LBP and is sufficiently sensitive to monitor these changes. ODI score was calculated as a percentage indicating the patients' levels of functional disability [23, 24]. All outcomes were measured before treatment and 4 weeks after treatment.

\section{Procedures}

The patients were randomly assigned into 3 equal groups $(n=20)$. All participants received conventional physical therapy treatment, which consisted of infrared on the lower back muscles for 15 minutes and static stretching exercises for the lower back, hamstring, and iliopsoas muscles. Static stretching involved 3 sets of 3 repetitions for each muscle with a 30-second hold and 30-second rest interval for each repetition [25].

Group A received conventional physical therapy treatment in addition to RST. The RST technique applied in this study involved alternating isometric contractions of trunk flexors and extensors for 5 seconds each. The patient sat facing the therapist. The therapist applied bilateral manual resistance just below the clavicles and asked the subject to flex the trunk. Isometric contraction was maintained for $5 \mathrm{sec}-$ onds, then the therapist shifted one hand just behind the shoulder and provided resistance to trunk extensors. As the patient initiated trunk extension, the therapist moved the other hand posteriorly and provided resistance bilaterally against trunk extension for 5 seconds [10].

Group B received conventional physical therapy treatment in addition to the $\mathrm{COI}$ training technique. The patient sat at the side of the plinth. The therapist asked the subject to flex the trunk while the therapist resisted the movement manually. When the participant's trunk was flexed to end range, they were asked to hold against resistance. This was followed by eccentric contraction as the therapist pushed the trunk slowly towards extension and the patient allowed the movement to go slowly while holding contraction of trunk flexors [11].

Group $\mathrm{C}$ received conventional physical therapy treatment in addition to RST followed by the COI technique. Each technique was performed for 3 sets of 15 repetitions. A $60-\mathrm{sec}-$ ond rest was allowed between the sets [17]. For all patients, 
the treatment was given for 4 weeks, 3 sessions per week, and every other day.

\section{Statistical analysis}

The data were analysed with the SPSS software (version 22) for Windows. Means and standard deviations were reported for demographic data and outcome variables. To compare the dependent variables under investigation within groups at the pre-test and post-test assessment times, a dependent $t$-test was applied. Analysis of variance (ANOVA) with Tukey's honest significant difference (HSD) post-hoc test was used to assess the differences between mean values of the studied variables among the 3 groups. The significance level was set at alpha $<0.05$.

\section{Ethical approval}

The research related to human use has complied with all the relevant national regulations and institutional policies, has followed the tenets of the Declaration of Helsinki, and has been approved by the relevant ethical committee (approval No.: P.T.REC/012/002507).

\section{Informed consent}

Informed consent has been obtained from all individuals included in this study.

\section{Results}

As indicated by ANOVA, there were no significant differences $(p>0.05)$ among the groups regarding the patients' demographic characteristics (Table 1).

The mean values of all outcomes in the pre-test condition presented no significant differences $(p>0.05)$ among the groups, as indicated by ANOVA (Table 2).

The comparison of the pre-test vs. post-test mean values for each dependent variable in each group showed significant differences $(p<0.05)$, as indicated by dependent t-test (Table 3). Also, the percentage of improvement for each variable was presented in Table 3.

The comparison of the mean values for the measured outcomes in the post-test condition showed significant differences $(p<0.05)$ among the groups, as indicated by ANOVA (Table 4).

Tukey's HSD post-hoc test revealed significant differences between group pairs for all measured variables, as shown in Table 5.

\section{Discussion}

This study investigated the effects of different PNF techniques on trunk muscle endurance, spinal mobility, and functional impairment in patients suffering from chronic LBP. The results revealed a significant improvement of both trunk muscles endurance and spinal mobility accompanied by a significant reduction of disability level after 4 weeks of treatment in all groups under investigation.

The significant improvement which occurred in the measured outcomes in the current study after 4 weeks of treatment could be attributed to the different PNF techniques used in the study in addition to the conventional physical therapy program applied in all investigated groups. However, the significant variation differences in the measured outcomes among the groups could be attributed to the specific type of PNF technique implemented in each group.

The COI group exhibited a higher statistically significant improvement in the investigated parameters than the RST group after 4 weeks of treatment. Furthermore, the combination of RST and COI showed a highly statistically significant improvement $(p<0.05)$ in all of the measured outcomes in comparison with the other groups which utilized either RST or COI alone.

The outcomes of the current study are in agreement with previous studies which reported a significant improvement after training with either RST or COI techniques, with more adventurous results for the COI groups over RST groups

Table 1. Patients' demographic data

\begin{tabular}{|c|c|c|c|c|c|}
\hline \multirow{2}{*}{ Characteristics } & \multirow{2}{*}{$\begin{array}{c}\text { Group A } \\
(\text { mean } \pm S D)\end{array}$} & \multirow{2}{*}{$\begin{array}{c}\text { Group B } \\
(\text { mean } \pm S D)\end{array}$} & \multirow{2}{*}{$\begin{array}{c}\text { Group C } \\
(\text { mean } \pm S D)\end{array}$} & \multicolumn{2}{|c|}{ Comparison } \\
\hline & & & & $F$ & $p$ \\
\hline Age (years) & $39.11 \pm 9.60$ & $38.09 \pm 8.80$ & $38.75 \pm 7.45$ & 0.071 & 0.931 \\
\hline Weight (kg) & $79.89 \pm 4.52$ & $80.31 \pm 3.85$ & $80.70 \pm 5.01$ & 0.163 & 0.849 \\
\hline Height $(\mathrm{cm})$ & $161.15 \pm 4.22$ & $160.28 \pm 5.19$ & $163.20 \pm 6.09$ & 1.648 & 0.201 \\
\hline Body mass index $\left(\mathrm{kg} / \mathrm{m}^{2}\right)$ & $30.82 \pm 1.54$ & $31.37 \pm 1.69$ & $30.45 \pm 1.38$ & 1.803 & 0.174 \\
\hline Gender ( $n$, males/females) & $11 / 9$ & $10 / 10$ & $11 / 9$ & - & - \\
\hline
\end{tabular}

$p>0.05$ indicates no significance

Table 2. Pre-test comparison of the mean values of the outcome parameters among groups

\begin{tabular}{|c|c|c|c|c|c|}
\hline \multirow{2}{*}{ Variables } & \multirow{2}{*}{$\begin{array}{c}\text { Group A } \\
(\text { mean } \pm S D)\end{array}$} & \multirow{2}{*}{$\begin{array}{c}\text { Group B } \\
(\text { mean } \pm S D)\end{array}$} & \multirow{2}{*}{$\begin{array}{c}\text { Group C } \\
(\text { mean } \pm S D)\end{array}$} & \multicolumn{2}{|c|}{ Comparison } \\
\hline & & & & $F$ & $p$ \\
\hline Trunk flexion endurance (s) & $24.31 \pm 2.14$ & $23.98 \pm 1.99$ & $25.15 \pm 2.55$ & 1.452 & 0.242 \\
\hline Trunk extension endurance (s) & $32.89 \pm 3.94$ & $33.23 \pm 3.37$ & $34.09 \pm 4.12$ & 0.523 & 0.595 \\
\hline Flexion spinal mobility (cm) & $3.45 \pm 0.85$ & $3.37 \pm 0.65$ & $3.29 \pm 0.73$ & 0.228 & 0.796 \\
\hline Extension spinal mobility (cm) & $1.28 \pm 0.29$ & $1.19 \pm 0.18$ & $1.15 \pm 0.22$ & 1.613 & 0.208 \\
\hline Functional impairment (\%) & $24.75 \pm 3.16$ & $23.99 \pm 2.95$ & $25.24 \pm 2.49$ & 0.968 & 0.385 \\
\hline
\end{tabular}


Table 3. Pre-test vs. post-test mean values comparison for the measured outcomes

\begin{tabular}{|c|c|c|c|c|c|}
\hline Variables & Group & $\begin{array}{l}\text { Before treatment } \\
\quad(\text { mean } \pm S D)\end{array}$ & $\begin{array}{l}\text { After treatment } \\
(\text { mean } \pm S D)\end{array}$ & $p$ & $\begin{array}{l}\text { Percentage } \\
\text { of improvement }\end{array}$ \\
\hline \multirow{3}{*}{ Trunk flexion endurance (s) } & A & $24.31 \pm 2.14$ & $36.54 \pm 3.41$ & $<0.001$ & $50.30 \%$ \\
\hline & B & $23.98 \pm 1.99$ & $39.63 \pm 3.24$ & $<0.001$ & $65.26 \%$ \\
\hline & C & $25.15 \pm 2.55$ & $44.72 \pm 4.18$ & $<0.001$ & $77.81 \%$ \\
\hline \multirow{3}{*}{ Trunk extension endurance (s) } & A & $32.89 \pm 3.94$ & $41.65 \pm 3.95$ & $<0.001$ & $26.63 \%$ \\
\hline & B & $33.23 \pm 3.37$ & $45.84 \pm 4.46$ & $<0.001$ & $37.94 \%$ \\
\hline & C & $34.09 \pm 4.12$ & $52.13 \pm 4.97$ & $<0.001$ & $52.91 \%$ \\
\hline \multirow{3}{*}{ Flexion spinal mobility $(\mathrm{cm})$} & A & $3.45 \pm 0.85$ & $4.56 \pm 1.06$ & $<0.001$ & $32.17 \%$ \\
\hline & B & $3.37 \pm 0.65$ & $5.49 \pm 0.98$ & $<0.001$ & $62.90 \%$ \\
\hline & C & $3.29 \pm 0.73$ & $6.29 \pm 1.07$ & $<0.001$ & $91.18 \%$ \\
\hline \multirow{3}{*}{ Extension spinal mobility $(\mathrm{cm})$} & A & $1.28 \pm 0.29$ & $1.85 \pm 0.18$ & $<0.001$ & $44.53 \%$ \\
\hline & B & $1.19 \pm 0.18$ & $2.01 \pm 0.22$ & $<0.001$ & $68.90 \%$ \\
\hline & C & $1.15 \pm 0.22$ & $2.16 \pm 0.16$ & $<0.001$ & $87.82 \%$ \\
\hline \multirow{3}{*}{ Functional impairment (\%) } & A & $24.75 \pm 3.16$ & $14.66 \pm 1.37$ & $<0.001$ & $40.76 \%$ \\
\hline & B & $23.99 \pm 2.95$ & $13.65 \pm 1.28$ & $<0.001$ & $43.10 \%$ \\
\hline & C & $25.24 \pm 2.49$ & $11.42 \pm 0.98$ & $<0.001$ & $54.75 \%$ \\
\hline
\end{tabular}

$p<0.05$ indicates significance

Table 4. Post-test mean values comparison for the measured outcomes

\begin{tabular}{|c|c|c|c|c|c|}
\hline \multirow{2}{*}{ Variables } & \multirow{2}{*}{$\begin{array}{c}\text { Group A } \\
(\text { mean } \pm S D)\end{array}$} & \multirow{2}{*}{$\begin{array}{c}\text { Group B } \\
(\text { mean } \pm S D)\end{array}$} & \multirow{2}{*}{$\begin{array}{c}\text { Group C } \\
(\text { mean } \pm S D)\end{array}$} & \multicolumn{2}{|c|}{ Comparison } \\
\hline & & & & $F$ & $p$ \\
\hline Trunk flexion endurance (s) & $36.54 \pm 3.41$ & $39.63 \pm 3.24$ & $44.72 \pm 4.18$ & 25.85 & $<0.001$ \\
\hline Trunk extension endurance (s) & $41.65 \pm 3.95$ & $45.84 \pm 4.46$ & $52.13 \pm 4.97$ & 27.72 & $<0.001$ \\
\hline Flexion spinal mobility $(\mathrm{cm})$ & $4.56 \pm 1.06$ & $5.49 \pm 0.98$ & $6.29 \pm 1.07$ & 13.92 & $<0.001$ \\
\hline Extension spinal mobility $(\mathrm{cm})$ & $1.85 \pm 0.18$ & $2.01 \pm 0.22$ & $2.16 \pm 0.16$ & 13.55 & $<0.001$ \\
\hline Functional impairment (\%) & $14.66 \pm 1.37$ & $13.65 \pm 1.28$ & $11.42 \pm 0.98$ & 34.06 & $<0.001$ \\
\hline
\end{tabular}

$p<0.05$ indicates significance

Table 5. Tukey's honest significant difference post-hoc test among the 3 groups

\begin{tabular}{|c|c|c|c|}
\hline Variables & Group pairs & Mean difference & $p$ \\
\hline \multirow{3}{*}{ Trunk flexion endurance (s) } & A vs. $B$ & 3.09 & 0.025 \\
\hline & A vs. C & 8.18 & $<0.001$ \\
\hline & B vs. C & 5.09 & $<0.001$ \\
\hline \multirow{3}{*}{ Trunk extension endurance (s) } & A vs. $B$ & 4.20 & 0.012 \\
\hline & A vs. C & 10.48 & $<0.001$ \\
\hline & B vs. C & 6.29 & $<0.001$ \\
\hline \multirow{3}{*}{ Flexion spinal mobility (cm) } & A vs. $B$ & 0.93 & 0.017 \\
\hline & A vs. C & 1.73 & $<0.001$ \\
\hline & B vs. C & 0.80 & 0.046 \\
\hline \multirow{3}{*}{ Extension spinal mobility $(\mathrm{cm})$} & A vs. $B$ & 0.16 & 0.025 \\
\hline & A vs. C & 0.31 & $<0.001$ \\
\hline & B vs. C & 0.15 & 0.038 \\
\hline \multirow{3}{*}{ Functional impairment (\%) } & A vs. $B$ & 1.01 & 0.025 \\
\hline & A vs. C & 3.24 & $<0.001$ \\
\hline & B vs. C & 2.23 & $<0.001$ \\
\hline
\end{tabular}


$[9,26,27]$. However, to the best of our knowledge, no previous studies tried to investigate the combined effect of both static and dynamic techniques of PNF on chronic nonspecific LBP.

The significant improvement in static trunk muscle endurance could be explained on the basis of the substantial muscle work performed in either technique of exercises, which is done at a progressively increasing intensity and adjusted to each patient's performance capacity. Eventually, this would show the improvements in muscle strength and endurance [28].

The improvement in spinal mobility after training with both forms of exercises would be explained on the basis of the effect of either technique on inhibiting muscle activity and inducing relaxation. Consequently, this might allow higher flexibility and overall trunk mobility [29, 30].

Another likely explanation of the improvements seen in this study is the reported relation between the development of LBP and disturbances in the local and central proprioceptive functions. Accordingly, patients who suffer from chronic back pain, reduced spinal mobility, and functional impairments may benefit from exercises that improve back proprioception [31, 32].

A potential causative factor in developing chronic LBP is reduced trunk muscle endurance [32]. So, the decreased level of functional impairment measured by ODI could be a direct effect of improvement in spinal mobility and trunk muscle endurance [26].

The higher percentages of improvement in the measured variables in group $C$ could be attributed to the fact that the patients in this group benefited from the advantages of both static and dynamic PNF techniques and exercised for longer durations compared with the other groups.

\section{Limitations}

A limitation of the current study is the short-term follow-up. To ensure the long-term effects of the applied techniques, both stand-alone and in combination as applied in this study, longer follow-up duration is recommended in future studies.

\section{Conclusions}

The application of the RST static technique of PNF followed by the COI dynamic PNF technique is more effective in clinical practice for the treatment of patients with chronic nonspecific LBP than the implementation of a static or dynamic PNF pattern alone. This arrangement should be taken into consideration by clinicians when treating such cases.

\section{Disclosure statement}

No author has any financial interest or received any financial benefit from this research.

\section{Conflict of interest}

The authors state no conflict of interest.

\section{References}

1. Bin Homaid M, Abdelmoety D, Alshareef W, Alghamdi A, Alhozali F, Alfahmi N, et al. Prevalence and risk factors of low back pain among operation room staff at a tertiary care center, Makkah, Saudi Arabia: a cross-sectional study. Ann Occup Environ Med. 2016;28:1; doi: 10.1186/ s40557-016-0089-0.

2. Shafizadeh M. Movement coordination during sit-to-
3. Grabois M. Management of chronic low back pain. Am J Phys Med Rehabil. 2005;84(3 Suppl.):S29-S41; doi: 10.1097/01.PHM.0000154908.76436.C2.

4. Balagué F, Mannion AF, Pellisé F, Cedraschi C. Nonspecific low back pain. Lancet. 2012;379(9814):482-491; doi: 10.1016/S0140-6736(11)60610-7.

5. Dąbek J, Piotrkowicz J, Korzeń D, Gąsior Z. Knowledge and use of ergonomic principles in physicians and nurses with low back pain. Health Prob Civil. 2019;13(3):217224; doi: 10.5114/hpc.2019.81342.

6. Kofotolis N, Sambanis M. The influence of exercise on musculoskeletal disorders of the lumbar spine. J Sports Med Phys Fitness. 2005;45(1):84-92.

7. Endamlı DB, Bayramlar K, Turhan B. Investigation of fascial treatment effectiveness on pain, flexibility, functional level, and kinesiophobia in patients with chronic low back pain. Physiother Quart. 2019;27(3):1-5; doi: 10.5114/ pq.2019.86461.

8. May S, Johnson R. Stabilization exercises for low back pain: a systematic review. Physiotherapy. 2008;94(3): 179-189; doi: 10.1016/j.physio.2007.08.010.

9. Kofotolis N, Kellis E. Effects of two 4-week proprioceptive neuromuscular facilitation programs on muscle endurance, flexibility, and functional performance in women with chronic low back pain. Phys Ther. 2006;86(7):10011012; doi: 10.1093/ptj/86.7.1001.

10. Kofotolis N, Vrabas IS, Kalogeropoulou E, Sambanis M, Papadopoulos C, Kalogeropoulos I. Proprioceptive neuromuscular facilitation versus isokinetic training for strength, endurance and jumping performance. J Hum Mov Studies. 2002;42(2):155-165.

11. Kofotolis N, Vrabas IS, Vamvakoudis E, Papanikolaou A, Mandroukas K. Proprioceptive neuromuscular facilitation training induced alterations in muscle fibre type and cross sectional area. Br J Sports Med. 2005;39(3):e11; doi: 10.1136/bjsm.2004.010124.

12. Hides JA, Jull GA, Richardson CA. Long-term effects of specific stabilizing exercises for first-episode low back pain. Spine. 2001;26(11):E243-E248; doi: 10.1097/000 07632-200106010-00004.

13. Koumantakis GA, Watson PJ, Oldham JA. Trunk muscle stabilization training plus general exercise versus general exercise only: randomized controlled trial of patients with recurrent low back pain. Phys Ther. 2005;85(3):209225; doi: 10.1093/ptj/85.3.209.

14. Luomajoki $\mathrm{H}$, Kool J, de Bruin ED, Airaksinen O. Improvement in low back movement control, decreased pain and disability, resulting from specific exercise intervention. Sports Med Arthrosc Rehabil Ther Technol. 2010;2:11; doi: 10.1186/1758-2555-2-11.

15. Macedo LG, Latimer J, Maher CG, Hodges PW, Nicholas $\mathrm{M}$, Tonkin L, et al. Motor control or graded activity exercises for chronic low back pain? A randomised controlled trial. BMC Musculoskelet Disord. 2008;9:65; doi: 10.1186/1471-2474-9-65.

16. Maher CG, Latimer J, Hodges PW, Refshauge KM, Moseley GL, Herbert RD, et al. The effect of motor control exercise versus placebo in patients with chronic low back pain [ACTRN012605000262606]. BMC Musculoskelet Disord. 2005;6:54; doi: 10.1186/1471-2474-6-54.

17. Voss DE, lonta MK, Meyers BJ. Proprioceptive neuromuscular facilitation: patterns and techniques, $3^{\text {rd }}$ ed. New York: Harper \& Row; 1985.

18. Saliba VL, Johnson GS, Wardlaw C. Proprioceptive neuromuscular facilitation. In: Basmajian JV, Nyberg RE (eds.), Rational manual therapies. Baltimore: Williams \& Wilkins; 1992; 243-284. 
19. Malliou P, Gioftsidou A, Beneka A, Godolias G. Measurements and evaluations in low back pain patients. Scand J Med Sci Sports. 2006;16(4):219-230; doi: 10.1111/ j.1600-0838.2005.00504.x.

20. Reiman MP, Krier AD, Nelson JA, Rogers MA, Stuke ZO, Smith BS. Comparison of different trunk endurance testing methods in college-aged individuals. Int J Sports Phys Ther. 2012;7(5):533-539.

21. Demoulin C, Vanderthommen M, Duysens C, Crielaard J-M. Spinal muscle evaluation using the Sorensen test: a critical appraisal of the literature. Joint Bone Spine. 2006;73(1):43-50; doi: 10.1016/j.jbspin.2004.08.002.

22. Bronner $\mathrm{S}$. Functional rehabilitation of the spine: the lumbopelvis as a key point of control. In: Brownstien B, Bronner S (eds.), Functional movement in orthopaedic and sports physical therapy: evaluation, treatment, and outcomes. New York: Churchill Livingstone; 1997; 141-190.

23. Algarni AS, Ghorbel S, Jones JG, Guermazi M. Validation of an Arabic version of the Oswestry index in Saudi Arabia. Ann Phys Rehabil Med. 2014;57(9-10):653-663; doi: 10.1016/j.rehab.2014.06.006.

24. Guermazi M, Mezghani M, Ghroubi S, Elleuch M, Ould Sidi Med A, Poiraudeau S, et al. The Oswestry index for low back pain translated into Arabic and validated in an Arab population [in French]. Ann Readapt Med Phys. 2005:48(1):1-10; doi: 10.1016/j.annrmp.2004.06.055.

25. Kachanathu SJ, Alenazi AM, Seif HE, Hafez AR, Alroumim MA. Comparison between Kinesio taping and a traditional physical therapy program in treatment of nonspecific low back pain. J Phys Ther Sci. 2014;26(8):11851188; doi: 10.1589/jpts.26.1185.

26. Hosseinifar M, Akbari A, Ghiasi F, Shamsoaldini N, Shahraki R. The effects of proprioceptive neuromuscular facilitation exercises on pain, function, lumbar mobility, and lumbar lordosis in patients with non-specific chronic low back pain. Int J Pharm Res Allied Sci. 2016;5(4): 250-261.

27. Franklin CVJ, Kalirathinam D, Palekar T, Nathani N. Effectiveness of PNF training for chronic low back pain. J Nurs Health Sci. 2013;2(4):41-52; doi: 10.13140/2.1. 1213.2486.

28. Fleck SJ, Kraemer WJ. Resistance training: basic principles (part 1 of 4). Phys Sportsmed. 1988;16(3):160-171; doi: 10.1080/00913847.1988.11709461.

29. Lusting SA, Ball TE, Looney M. A comparison of two proprioceptive neuromuscular facilitation techniques for improving range of motion and muscular strength. Isokinet Exerc Sci. 1992;2(4):154-159; doi: 10.3233/IES1992-2402.

30. Osternig LR, Robertson RN, Troxel RK, Hansen P. Differential responses to proprioceptive neuromuscular facilitation (PNF) stretch techniques. Med Sci Sports Exerc. 1990;22(1):106-111.

31. Van Tulder M, Malmivaara A, Esmail R, Koes B. Exercise therapy for low back pain: a systematic review within the framework of the Cochrane Collaboration back review group. Spine. 2000;25(21):2784 -2796; doi: 10.1097/00 007632-200011010-00011.

32. Biering-Sørensen F. Physical measurements as risk indicators for low-back trouble over a one-year period. Spine. 1984;9(2):106-119; doi: 10.1097/00007632-198 403000-00002. 